\title{
A Postdigital Exploration of Online Postgraduate Learning in Healthcare Professionals: A Horizontal Conception
}

\author{
Gillian Aitken ${ }^{1}$ \\ Published online: 5 February 2020 \\ (C) The Author(s) 2020
}

\begin{abstract}
Holistic evaluation of educational quality necessitates considering novel and theorized measures of quality as well as more instrumental metrics. Online learning is increasingly valued by working professionals as a means of gaining a postgraduate qualification while employed, but this area of education is undertheorized and investigated. Online learning is often discussed in instrumental terms, as if abstracted from the social and material settings in which learning and work take place, but my own conversations with student and graduates about the impact of their studies contrast strongly with such views and motivated this work. Adopting a postdigital perspective, I present an activity theory analysis of interviews with students and staff about the value and perceived impact of online postgraduate programmes in healthcare professions. Four themes are identified that describe how students learning moves horizontally within and across academic and clinical settings: crossing boundaries, ripple effect, eroding structures and hierarchies and expansion. Teaching is delivered online, but learning occurs as the students move through the various contexts they inhabit. The pedagogical approaches required to realize the potential value of these programmes should not be based on the online delivery or the technologies used, but the particular needs of the student group.
\end{abstract}

Keywords Postdigital $\cdot$ Postgraduate $\cdot$ Online learning $\cdot$ Activity theory $\cdot$ Healthcare professional $\cdot$ Holistic evaluation

\section{Introduction}

Conversations with students, both during and after their studies, offer a rich source of data that can provide helpful insights into the impact of studies beyond the academic

Gillian Aitken

gill.aitken@ed.ac.uk

1 Edinburgh Medical School: Medical Education, University of Edinburgh, Edinburgh, UK 
institution. Theorized considerations of quality can support data and analysis needed in holistic evaluation. Such data are particularly important in online postgraduate taught degree (PGT) evaluation as instrumental views of online learning put online postgraduate degrees at risk of being regarded solely for their income generating potential by academic institutions, rather than valuing the potential educational benefits. The commodification of higher education in the current neoliberal, expansionist and market-led agenda (Jones 2019) is well-illustrated in this area with staff under pressure to increase recruitment.

Postgraduate degrees are increasingly seen as a means of career advancement in increasingly competitive professional promotion processes. Increasing student demand and online delivery offers the potential to expand student numbers and thus income. Online delivery also allows individuals to access education from anywhere in the world while continuing in gainful employment, but the part-time delivery and professional nature of the student group are as important as the mode of delivery to the learning environment. Such degrees can be considered to operate at the boundaries of academic and professional settings (Aitken and O'Carroll forthcoming 2020).

Part-time study allows learners to move backwards and forwards between academic and professional environments over a number of years affording the opportunity for relationships to build. In this way, they are very different to traditional taught 1 year oncampus masters' degrees that often follow on straight from undergraduate study. This part-time mode of study is potentially as important as the online delivery to any potential impact on learning but has received little attention to date in the literature (Jamieson et al. 2009). Kember and Leung (2005) reported that part-time postgraduate students on applied professional programmes generally see academic staff as fellow professionals, hinting at a more equal relationship between educators and students. While superficially online postgraduate programmes may be considered only in terms of their online delivery, this overly reductionist view fails to consider both the length of time such studies take as students work and study concurrently and that students tend to already be established professionals. A postdigital view considers that the online world is not separated from other aspects of human life but is interwoven in messy and unpredictable ways (Jandrić et al. 2018).

The development of expertise is often conceived of vertically; see, for example, Miller (1990) or linear progression through stages to achieve expert status (Dreyfus 2004). Expertise can be gained by an individual in a bottom-up approach, shared by those considered as experts in a top-down manner (Collins 1990) or some combination of both. Considering expertise to have a horizontal as well as vertical aspect acknowledges that professionals rarely operate in one context and increasingly need the ability to navigate, negotiate and manage various, often conflicting, contexts and systems, referred to as polycontextuality (Engeström et al. 1995: 320). Such horizontal conceptions are useful when considering professional education to appreciate the more egalitarian nature of such education.

By definition, online learning requires technology for its delivery, but it is not technology that facilitates the collaborative and questioning approach adopted in some programmes. Educators encourage interaction, sharing of experiences and understanding of the wider social, cultural and environment students inhabit. Given the cultural and professional diversity within the students in online programmes, this can be challenging, and technology alone cannot deliver this; human endeavour is required. 
Online postgraduate teaching is designed, delivered and curated in the academic setting by academic staff, but learning potentially occurs in many settings as learners move through the various environments that they inhabit, making connections between their academic and clinical experiences. This dynamic conceptualization allows us more clearly to appreciate the potentially expansive learning nature of online learning, particularly in this group of working professionals. While this makes intuitive sense, there is a lack of information on how this works in practice. This paper explores some of the factors required to successfully facilitate this process by exploring the experiences of both students and staff currently involved in online postgraduate education, focusing on human interaction allowed by the use of technology through an activity theory lens.

\section{Theoretical Framework}

Activity theory has been proposed as a way of 'transcending the dualisms' present in much philosophical thought (Engeström and Miettinen 1999: 5), for example, between theory and practice or thought and activity. While social scientists have traditionally separated socio-economic studies from those of individual's behaviour, activity theory attempts to link individual and social structures.

This is an evolving area of research, and several generations of activity theory exist. In its simplest conceptualization, first-generation activity theory conceptualizes interactions between three elements, a subject that interacts with the environment through materials or artefacts to produce an object leading to an outcome. Within online postgraduate study, the subject could be a student or teacher, the artefact a computer or virtual learning environment, and the object the award of an academic degree or development as an educator. First-generation theory has been extended to further consider the community in which the activity takes place, the rules governing the activity and the division of labour within the community (second-generation) (Engeström 1987). Engeström's third-generation activity theory allows a more expansive systems approach that considers factors such as the potential impact of cultural differences in a minimum of two activity systems.

\section{Methods}

\section{Data Collection}

Fifteen members of academic staff, from three UK institutions who are currently involved in delivering online postgraduate courses to healthcare professionals, were asked about their experiences of teaching this group. Thirteen work at the University of Edinburgh. Preliminary results from these interviews were shared with colleagues from other institutions as a means of sense checking, and two further interviews were undertaken, one with a colleague from the University of Newcastle and one from the University of Glasgow. The Edinburgh interviews were carried out in person the other interviews conducted online. Programmes represented included Surgical Sciences, Pain Management, Public Health, Clinical Psychology, Internal Medicine, Global Health, Veterinary Studies and Clinical Education. Interviews were undertaken by a $\mathrm{PhD}$ intern whose time was paid for by a small institutional educational grant. Staff were invited to 
participate by email to all staff thought to be in a relevant role, the numbers of staff in the institution involved in delivering online PGT is unclear.

Those interviewed had a mean age of 47 years, with considerable teaching experience. Ten participants were female, all had professional backgrounds relevant to the subjects they taught: nursing, clinical psychology, medicine, basic science, physiotherapy and veterinary medicine.

All students completing the first year of the MSc Clinical Education at the University of Edinburgh were also invited to participate, and eleven students from the academic year 2017/2018 and seven from the academic year 2018/2019 agreed to take part. Intake to the first year of the programme is currently around ninety students. Interviews were undertaken online. Students are all qualified in a health profession and are actively involved in clinical teaching. Four were male, 11 were based in Europe, 3 in Africa, 3 in Asia and 1 in North America. Age ranged from 25 to 60 with considerable variation in clinical experience from 2 to 30 years. Most (11) were medically qualified with 3 nurses, 1 pharmacist, 1 dentist and 2 educationalists.

\section{Data Analysis}

Institutional ethical approval was obtained, and participants gave informed consent. Interviews were audio-recorded, and recordings were professionally transcribed and thematically analysed using the approach described by Braun and Clarke (2006). Initial coding from the student interviews was carried out, resulting codes were combined and used to identify emerging themes and generate an initial coding framework. These were then compared and iteratively refined as the data from the staff interviews were collected. Two interviews with academic staff from other institutions were undertaken to ascertain if the themes had relevance beyond the institution. The emergent themes were echoed between the two groups of interviewees and strongly articulated by many participants. In the second phase of analysis, these themes were viewed through the theoretical lens of activity theory to allow a more expansive socio-material consideration of the data. Within this second phase, a postdigital sensibility (Fawns 2019) informed the way in which digital technology was seen within each activity system (i.e. as embedded within social and material activity, rather than separate from it).

My role as Programme Director of the MSc Clinical Education must be acknowledged. While not involved in data collection, I am the senior academic staff member responsible for the programme that the students are being asked about and a colleague of those in study 1 . Recognition that the resultant analysis is a co-construction of my impact as the researcher and the participants' experiences and perceptions is necessary. This is aligned with the premise of activity theory that individuals construct their activities through discussion and interaction and constructive results will be obtained by the hearing the researcher's voice in dialogue with the activity system under investigation (Engeström and Miettinen 1999).

\section{Results}

All students interviewed were clear about the benefits of their studies, and these were considered not only to result in personal transformations, impacting on individual 
practice, but also resulting in wider influence within workplaces, seen as extending beyond the academic award obtained. Staff were enthusiastic about their teaching, and this was largely related to the interaction with students and the effects they saw their teaching was having. Results very clearly described a perception of learning as a recursive process as students moved between the different activity systems they inhabit, with four clear themes identified:

- Crossing boundaries (explicitly between academic and practice settings).

- Ripple effect (influencing people beyond immediate course interactions).

- Eroding structures and hierarchies (building confidence to engage more, questioning the status quo, a perception of enhanced legitimacy).

- Expansion (of one's own thinking and one's collective networks of participation).

Conceptualizing learning as a horizontal process with students moving backwards and forwards over academic and clinical boundaries helps us to understand both the distributed nature of online postgraduate learning and its potential impact.

Each theme is explored from the student perspective (quotes attributed to the prefix S) and supported by a description of the actions by academic staff linked to the facilitation of the process (quotes attributed to the prefix E). Each theme is then explored through an activity theory lens. I represent the activity system of the postgraduate online programme in Fig. 1. Activity theory was applied in a deductive manner to the identified themes.

Figure 1 depicts my exploratory model of a postgraduate online learning system. Triangle 1 represents the activity system of a clinical environment, such as an anaesthetics department that each individual student inhabits. Triangle 2 represents the activity system of the online degree programme, and Triangle 3 represents an academic department, in which the programme staff operate. Activity systems 1 and 3 represent professional workplaces and system 2 where differing professional groups come together online. This allows a clear representation of the relevance of the boundaries

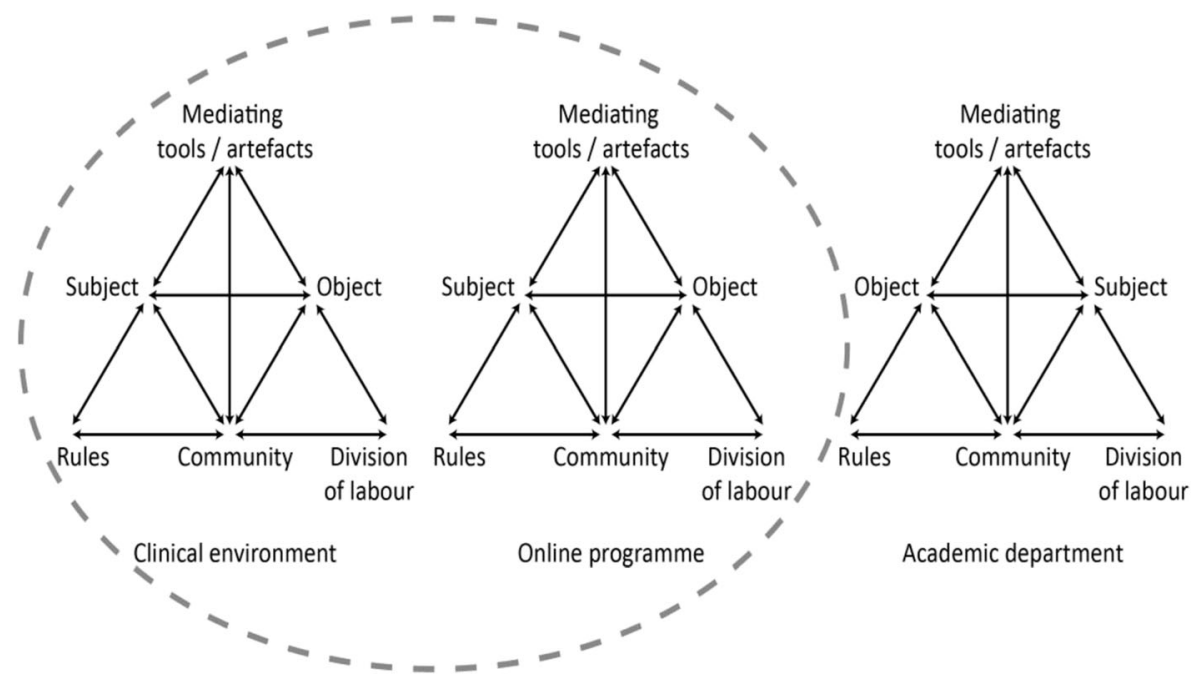

Fig. 1 Activity system of an online postgraduate programme 
of the various systems. The conceptualization of work allowed by activity theory allows us to see it as a collaborative activity with inherent tensions and contradictions, inherently messy with ill-defined boundaries. Clinicians engaging in online study still work within clinical and professional boundaries; thus there is a need for a separate activity system. Teachers work in academic institutions and are bound by their own activity systems which include their professional affiliations and academic regulations and conventions. They meet in the online setting crossing out of their professional context and meeting in a new educational environment then cross back into their professional system. The flexibility of online learning allows this movement to happen repeatedly.

This paper reviews activity system 2 from the lens of the student as the subject and the interaction between systems 1 and 2. While the focus here is on student experiences (as seen through systems 1 and 2), the views of staff are presented in relation to their participation in system 2. This is as members of the community and as contributors - through design choices and facilitation-to rules, divisions of labour and the mediating tools and artefacts that feature as structural elements of the programme.

Mediating tools and artefacts within the online programme might include course documentation, computers, internet, reading lists, course discussions and other methods of interaction. Importantly, these tools and artefacts do not have effects or actions in isolation of the context in which they are used. Rather, they are embedded in particular postdigital ecologies in which students and staff integrate them into established practices and cultures (Fawns 2019). As such, tools and artefacts will vary in the different activity systems and may impact multiple activity system. For example, feedback on an assignment (artefact in the online activity system) may encourage the student to alter their teaching thus affecting the community or division of labour in their clinical activity system.

Rules include curricula and academic regulations; for staff, this will include role modelling of informal programme conventions. Staff will also be subject to institutional drivers and policies, as well as students who may be studying as a result of regulatory body policies. Rules are not only important in individual activity systems but also can be understood to be carried between systems in the professional behaviours of staff groups.

Community includes students on the programme, programme staff, tutors, administrative staff (clinical colleagues for students) and other university staff or teachers.

Division of labour describes who is doing what, students learn individually and in groups, students complete assessed work, staff deliver content, staff engender an open environment, staff assess work, and staff provide constructive feedback.

It should be recognized that this is a highly stylized representation of what is a dynamic and evolving process, recognizing that all students and staff come with their own individual needs, aspirations, concerns and motivations. Adopting an activity theory lens allows this interpretative framework to achieve a simplified representation of a complex area that illustrates how movements can occur between the various systems. At the same time, the postdigital perspective reminds us that each division is fluid and messy, since the agency, responsibility and activity of these tasks and relations are distributed across not only students, staff and other stakeholders but also policies, technologies, infrastructures, etc. 


\section{Crossing Boundaries}

Online study allows flexibility for students to dip in and out of their studies at different times and places as their schedule allows, accessing people and resources from multiple settings. It crosses boundaries because it is not located within either setting but spans both, so allowing professionals to move not only between academic and clinical settings contemporaneously but also spanning digital and non-digital settings. This is not seamless and requires considerable effort from the student and the staff supporting them. Knowledge does not move across boundaries in some disembodied way but is embodied in people as they move between contexts while reflecting and reconstructing their understanding. Understanding this division of labour (whether between staff and students or between students and students) in activity systems is key to ensuring a constructive learning environment is provided.

I liked the way the course allowed me to use discussions or learning that I'd done in the course and then bring it across to my own work and my own institution, so I think that was a huge benefit for me. It did not feel like it was separate to my work or my kind of academic work, so I think that was a huge benefit, just being able to integrate it into my kind of life, rather than have it as a separate component. I think that was really useful for me. (S07)

In this way, mediating artefacts in the online system, in this instance discussion board posts, were seen to influence the student's professional system.

Teaching staff were clear about the need for curricular design to be relevant to the clinical workplace, remaining cognizant of rules and division of labour in the clinical environment and also any specific requirements of relevant regulatory bodies.

So, when we are teaching clinicians, it's got to be relevant to their day-to-day world, it cannot be about what we think's interesting. It's got to be about what the clinicians find interesting, what will help them in their day-to-day world? (E02)

There was a clear focus on helping students' professional development, not merely delivering academic knowledge, with a sense of encouraging students to think creatively and question more. Consideration was shown by staff in choosing mediating artefacts that would more clearly encourage criticality in students. In this way, an outcome in the programme system has the potential to become a tool or object in the student's professional system, with mediating artefacts in system 2 influencing system 1 .

Linking it back to professional groundings and seeing how this gaze enables you to do things differently, impact on a pathway, looks at innovation, making you into an agile professional. So, curiosity, I think it's a skill that you have, you can nurture. (E09) 
The challenges of combining work and study were acknowledged with a clear need to consider the needs of this particular student group in programme design. Flexibility of delivery was considered key, with the ability to adapt to the needs of students that come with very different skills and experience, making a careful consideration of the rules of the programme activity system important.

\section{The Ripple Effect}

While learning is often perceived as an individual process, the benefits obtained often extend to the student's clinical activity system, clearly showing the importance of community in both activity systems. Examples were given of how the learning from these programmes is mobilized in the practice setting and that this is a collective mobilization rather than an individual one, with the student's enhanced voice influencing practices across their wider professional group.

My colleagues were...I think in one respect, they were happy for me to do the course because it's actually allowed them to have new ideas for their own classes. So, I could discuss with them about the things I had learnt or the things I had thought about, and then I think it gave them some interesting points as well. (S07).

Academic staff discussed designing mediating artefacts such as assignments and learning activities that challenged students to question their assumptions, reflect on practice and consider how best to utilize this new understanding in their own professional contexts. In this way, their impact was seen to extend beyond the individuals they taught.

Our whole ethos is really about moving people away from drinking up straightforward textbook learning, which doctors are quite good at that because there's an awful lot of it. But to start questioning what's going on out there and the kind of truths which are handed down to them from medical school. (E07)

Reinforcing that these programmes are bound up in real-world contexts and that postgraduate education is not just about technology or content delivery but encouraging an ethos of questioning and criticality and encouraging students to adopt a less individualistic approach. An important part of the teaching was inspiring students to see the bigger picture, form connections and ask better questions supported by the collective, discursive approach modelled in these programmes. In this way, the rules and division of labour of the programme activity system can be seen to have a clear impact on the professional activity system of the student.

\section{Eroding Structures and Hierarchies}

The focus on connections and discussions rather than technology resulted in academic staff being considered by students as mentors or more experienced colleagues rather 
than as more senior members of a hierarchy, and there was a clear sense of academic staff encouraging this near-peer perception of their role to encourage a more egalitarian relationship.

But I feel I like the long-term relationship where we can have a lot of back and forth. I would see them more like a mentor (S10)

Staff were very open to working in a collaborative way with students and allowing an open and democratic study environment and impacting on the division of labour and community within the activity system.

So, it's not seeing a student as a student, and you are the lecturer, just this, sort of, academic community, where conversations occur and people are learning. (E13)

I do not see them as students, I see them as colleagues, because they add a lot of value to our experiences on the programme. And actually, they help shape the development of the programme. (E08)

Programme development was seen as an iterative process, in a constant state of evolution. Partly this relates to knowledge not only being seen as fixed but also the acknowledgement that professional practice was perceived as being in constant evolution. In this way, mediating artefacts are continually reviewed and refined, and rules and division of labour is deliberated. Considering the ways in which students applied learning to their practice conveyed important elements of the practice context that could be incorporated into teachers' conceptions of the contemporary workplace and are an important way that lecturers stay up to date with professional developments.

So, we are geared towards enabling students to give us feedback and have a sense of power, that they can make changes. So, this kind of learning from previous students and understanding what fosters professional curiosity, that gives us the guide to develop current courses and have the understanding of how to do things better for future courses. (E09)

As alluded to earlier, the benefits of the study were considered often to spread to colleagues in the workplace. This was not just those at a similar developmental level, but participating in the programme resulted in enhanced confidence when interacting with more senior colleagues leading to a suggestion of flattening established professional hierarchies within the wider communities that students inhabit.

And when I first got my job and I met her and I was meeting up with the other senior educationalists that make up this faculty and, you know, manage all of the funding. They do a huge amount of work in the hospital with training and supporting the newly qualified staff and existing staff. And I felt deeply out of 
my depth whenever I was around them. And so, it's helped me on that level. I mean it really has. I do feel completely different when I'm in a room with them. (S06)

\section{Expansion}

The expansiveness theme can be considered both at an individual level and more widely within the clinical environment, by allowing students' space to think and also encouraging them to build relationships and links with others on the programme.

\section{Space to Think}

Interaction is encouraged in these programmes, and students' views are shared on discussion boards, and in other ways, this allows students the opportunity to make explicit what may previously only have been internal thoughts. Staff have a key role in facilitating this process and designing learning activities to encourage this. The opportunity for public rehearsal was considered key in developing confidence, while the act of writing ideas down or discussing them was seen to strengthen student's commitment to, and further develop of, these ideas. Such 'performativity' has been criticized for making a personal journey of learning into a publicly assessable artefact, but here this public rehearsal was considered to enhance individual self-efficacy. Careful consideration by educators was required to ensure the most appropriate mediating artefacts were employed. While space to think was valued, the need to consistently submit work (a tool) for assessment and feedback was also considered a necessary stage in the student's development.

It was the sitting down and writing it that made me commit to what I thought and be more reflective about what I actually do and whether those were intentional and in line with what I believe or whether I was just doing something out of rote practice. Yes, so it was the writing it made me identify what I believed. (S04)

I did the first essay, the one that was about teaching and learning theories, it felt as though it had opened up a huge doorway almost. It felt like everything started to make a lot more sense (S06)

Written work in this way can be considered a tool of system 2 that has an impact on system 1. Students can put their burgeoning theoretical understanding directly to use in their workplace, thus fuelling further developments of these insights. The outcomes of this experience, either positive or negative, can then be shared with others on the programme in system 2, again reinforcing the potential of the boundary-spanning nature of postgraduate study. By considering the division of labour element here, it can be seen that the onus is on the student to apply educational principles and methods to their professional context; the staff cannot do this for them. To facilitate this process, academic staff were clear in their view 
that postgraduate study should provide the space and opportunity to develop a questioning mindset.

Pick an assignment that's going to be relevant to your work, you know like, actually, do something that's going to be useful to you after you finish the course, rather than as a purely academic exercise. So, I think, there's that but also encouraging people to, maybe, it's a bit about encouraging people to question what their own profession does and, like, assumed knowledge within their profession. (E10)

Interestingly the assignment here was not only considered a tool but also a means of changing objects and questioning established rules inherent in the restrictive notion of assignments only for academic credit. There was a clear recognition that this questioning and open mindset applied equally to those delivering the programmes. It is relevant that most staff interviewed had come to an academic career after a previous career in the professions they now taught, so they themselves have personal experiences of moving between settings and challenging themselves in new areas, such as teaching online. The emphasis on scholarship in these programmes can be considered a tool but also a rule. The commitment to scholarship that is role-modelled by the staff in encouraging an open and questioning mindset suggests that staff do not see their role as merely passing on knowledge as defined in the curriculum.

And it is about scholarship as opposed to learning because there are more facets to scholarship than just learning. It is about teaching others. It is about accepting challenges, being challenged yourself, learning in a different environment.(E09)

\section{Community Building}

Students also considered the academic networks that these programmes of study provided to be advantageous. Members of an individual student's communities will vary but are likely to include programme staff, other students, administrative staff and clinical colleagues. In this way, online postgraduate study can be seen to expand the activity systems of individual students.

it's kind of broadened my network, my professional network of people whom I know, so I think that's a huge advantage. I feel I know people in other countries and people with experiences similar to my own, and people who have experiences completely different to my own. So, I think this is, in terms of career progression, a huge advantage. (S07)

This relates to the discursive nature of postgraduate study with students encouraged by rules and division of labour to bring their experiences to the academic environment, reflect, share and build on them. Online study was seen to offer opportunities to bring 
people together from very diverse backgrounds and locations in a way that is not possible in a traditional classroom, creating community. The powerful potential of online learning to build relationships was also acknowledged by staff, with further recognition that much of the learning occurred through sharing within the student group, reinforcing the need for activities that supported community development and encouraging students to see peers as a rich learning resource.

But what does surprise me is how much of a relationship you do form as well, especially when they come to graduation, you know, you feel like you have been their colleague for years, you know, so and what I find a lot is the peer to peer interaction is infectious because they are learning from each other's different health professional backgrounds as well and their day to day kind of, you know, journeys. And that's one of the biggest bits of feedback that we get is that they learn more from each other sometimes than they do from some of the, you know, some of the leaders on the programme even. (E08)

\section{Discussion}

Activity theory (Engeström 2005) was identified as a helpful framework to study the learning in online postgraduate programmes, due to their situation at the boundaries of academic and professional practice. By definition, activity systems have boundaries, and the potential for learning at boundaries has previously been described as profound (Akkerman 2011), introducing an externality that can facilitate new ways of seeing things, apparent in the experiences of this group of students. The experiences students bring to the academic environment can be used as valuable sources of learning and mechanisms to allow sharing and discussion of these experiences which are key to successful online postgraduate learning. While technologies provide structure and mediating artefacts for the learning environment, it is the efforts and interaction of individuals in combination with materials and technologies that result in the rich learning experiences discussed here. Rather than seeing the technologies and infrastructures that underpin these programmes as separate from educational activity, they are more productively seen as considerations that feed into design and teaching.

Crossing boundaries has been described as a process allowing ideas and experiences to be conveyed from one setting to another (Engeström et al. 1995). In this way, those from different professions can come together, as described by Cannon-Bowers et al. (1993) to develop 'shared mental models', developing a community of practitioners, or the 'contact zone' proposed by Kramsch (1993) to describe the learning and sharing between those from different cultures. The challenge for educators is to structure their teaching to allow the pedagogical space that Su (2014) refers to, allowing students' freedom and agency to engage actively in their own learning while building community.

The criticism of online learning as inherently impoverished in terms of the relations and interactions that occur there has previously been challenged (Fawns et al. 2019) suggesting that meaningful interactions can, and do occur online, but require creative 
pedagogical design and sufficient academic time to support community building. These results reinforce this view and consider how curricular design can encourage academic interactions that have direct benefits in the clinical workplace by allowing time and space for discussion and reflection. Technology is not determinate and requires social structures within which to operate (Woolgar 2002), and by considering the clinical environment and the academic setting as activity systems, individual student agency in their learning can be better understood by considering recursive movement between systems. The appeal of activity theory in this area is to very firmly foreground human endeavour in the postgraduate online activity system. Too often, technology is referred to uncritically when applied to educational settings, as evident in terms such as Technology Enhanced Learning that suggest that technology itself in some disembodied way enhances learning (Bayne 2015). At the same time, a postdigital perspective reminds us that the boundaries around and between activity systems are dynamic and ill-defined.

The role of technology in blurring boundaries between academic and social spheres has been discussed (Conole et al. 2008). Part-time online learning and the movement of students between settings that this allows does the same for professional and academic settings, developing students' identities as educators through dialogue (Thorpe and Edmunds 2011), pedagogical space and performativity. Recent work with online students (Aitken et al. 2019) specifically noted that the discipline required to produce assessments on a range of topics at regular intervals was a transformative experience amongst postgraduate students. However, this focus on assessment that fails to recognize that the whole learning experience is a formative one. Considering the wider activity systems allows us to see that it is not just production of written work but also the contributions to discussion boards, engaging in tutorials and other conversations as well as the ongoing dialogic feedback on work that all combines and contributes to this transformative experience. Bracketing assessment off as an 'event' downplays all the other interactions and runs the risk of downplaying the effort and time involved on both sides. Good pedagogical design maximizes opportunities for interaction and encourages students to reflect and link clinical and academic work enhancing their confidence in their own practice as clinical educators. This enhanced confidence results in a more questioning approach to clinical education which can help challenge existing structures, orthodoxies and hierarchies. Acknowledging and celebrating this diversity are in stark contrast to the current 'student experience buzz phrase' (Zepke 2014: 697) prevalent in higher education policy, which implies student experience as a singular, and not plural, entity. In this way, student engagement is reduced to a commodity that can be marketed by universities (Hayes 2018).

Reductionist standardization of quality by what is perceived as easily quantifiable means, focusing on student satisfaction and outcome measures as instrumental metrics, miss the potential value of the collaborative elements as reported here. This ecological, activity-based framework addresses some of the deficits common in more instrumental approaches (Fawns et al. forthcoming 2020). Considering, for example, the value of the collaborative nature of part-time, postgraduate study as described here both in terms of academic programme development and on longer-term outcomes, as practiced by graduates in the workplace offers such a holistic approach.

Exercises such as the Teaching Excellence Framework (TEF) represent an expansion of a measured market in the higher education sector (Tomlinson et al. 2018), in an 
attempt to enhance and develop the transparency of teaching quality. The current weight given to easily measurable outcome measures such as grades says very little about the quality of the teacher-student relationship, other than a tacit assumption that good relationships lead to good outcomes.

Similarly, standardized questions about teaching cannot deal with the ecological complexity described here, where teachers act at the interstices of the structural elements (rules, mediating artefacts, division of labour) inhabited by students. In doing so, good teachers aim to maintain an appropriate balance between structure and agency both for themselves and their students, knowing that too much direction constrains opportunities for students to develop autonomy, while too little leaves students to flounder, unsupported. These aspects of teaching are not always visible to students, and perhaps their quality can only be judged theoretically, as here. Conversations with students understanding their motivations and challenges in relation to their studies are important in planning and evaluating academic programmes. Programme leaders have to understand why students choose their programmes and what graduates do with their learning to ensure the continuing relevance of their programmes in an increasingly competitive market (Aitken and O'Carroll forthcoming 2020).

Here, technology offers opportunities in supporting the development of online communities that transcend the physical reach of the individual, allowing the sharing of experience and expanded worldview that offers insights far beyond that which could be experienced within the physical constraints of one individual. Thus, supporting the potential of an online learning community as a site for sharing disciplinary knowledge and discussion that can affect individual agency beyond the direct impact of the academy (Ferreday et al. 2006).

Taking an activity theory lens to online learning allows us to see some of the shortfalls in considering the learning that occurs here in merely socio-constructivist terms. Online learning communities can be referred to as communities of practice (Lave and Wenger 1991), but this fails to consider both the material and temporal insights that an activity theory exploration can offer. An individual on the periphery of a community and described as engaging in legitimate peripheral participation (Lave and Wenger 1991) intuitively helps us to understand the journey from novice to expert; however, the horizontal and recursive representation of the learning on online PGT programmes allows a more nuanced picture of the acquisition of professional knowledge, key as individuals move between settings. Considering the expansive nature of online learning highlights the importance of exposing students to critical discourse in their studies to enhance their curiosity and criticality and the potential impact on their wider professional group, described here as the ripple effect.

The distribution of power within the academy is undoubtedly weighted in favour of academic staff, despite the trend in recent decades towards the symbolic and actual reinvention of students as customers. This imbalance is moderated somewhat in postgraduate education by the fact that tutors and students are often fellow professionals (Kember and Leung 2005), enjoying a more equal relationship and thus allowing this horizontal conceptualization of online postgraduate education. While this can be seen to have clear educational benefits, it does take time and effort both from the student and the staff supporting them and cannot be seen as a seamless process. A factor often overlooked requiring wider acknowledgement within higher education institutions when considering the resource implications of online learning (Fawns 
et al. 2019). The current ascendency of the neoliberal agenda in higher education means the income generated by postgraduate programmes and their growth potential can result in institutional pressure to expand. There is a clear need to consider educational benefits as described here to ensure decisions are not made on purely financial grounds and more educators working in this field should be encouraged to share their experiences.

Activity theory is not without its critics, specifically that the triangular representation is at risk of reifying the constituent factors into distinct parts rather than a holistic focus on the whole (Langemeyer and Roth 2006); by looking at the system from the perspective of more than one subject, this pitfall has been avoided, and adopting a postdigital perspective helps resist the view of technology as being isolated from the expansive social and material activity of students and staff or from the wider ecologies and infrastructures in which these programmes are embedded. While the lack of prescription and clear guidelines may be considered a weakness of Engestrom's work, in undertheorized areas such as this, lack of prescription can be interpreted as allowing flexibility to interrogate complex areas of activity.

By considering the importance of individual agency, this exploration offers insights into why the effects of online postgraduate education can be so profound, both on individuals and the wider hierarchies which they occupy. The passivity inherent in the view of a student as someone who merely wishes to receive information as transmitted by a teacher (Hager and Hodkinson 2009) does not account for internal motivations and the desire to engage often present in postgraduate students. Similarly, the teacher's desire to educate and interact might be tempered by institutional drivers and policies that attempt to reduce teaching to measurable metrics as the teaching approach described here does take time and effort not easily quantified. These factors highlight the complexity of the area, and considering online postgraduate education as an area where traditional boundaries between academic staff and students are collapsing is a helpful conceptualization that is worthy of wider dissemination and appreciation, both in terms of the potential of individual learning in this area but also the expansive nature of such learning.

\section{Conclusion}

The motivations to write this paper came from conversations with many students who had anecdotally reported the value and impact of their studies in ways that differed from the kind of information captured in standard evaluation metrics, leading to questions as to why this might be the case. A theorized evaluation of quality rather than an instrumental one as described here recognizes the need to go beyond evaluations of the course and into evaluations of how students apply their learning (and continue to learn) within the workplace. This exploration suggests that both the parttime and the online delivery are important elements allowing the boundary crossing necessary to span different activity systems; however, this is contingent on appropriate pedagogy. Careful design of assignments, learning activities and other mediating artefacts that allow dialogue about practice encourages the linking of academic and clinical learning. By considering the recursive movement between the activity systems, we can more clearly see the ripple effect and online postgraduate education's potential impact. Building online community and allowing dialogic space to think are the 
pedagogical underpinnings that facilitate collective expansion in online postgraduate students. Despite the emphasis on efficiency and standardization in many implementations of educational technology, our results show that the promise of technology can be redeemed through pedagogical approaches that create sufficient space and agency for students to engage in the horizontal processes described here.

This conceptualization is not offered as a one-size-fits-all, and this will not be common to all those studying postgraduate degrees. Just as there is not one version of online learning (Fawns 2019), much will depend on the motivations of individual learners and curricular design of individual programmes of study, but the potential impact of online postgraduate should not be underestimated with these exploratory results offering important insights to those designing and delivering online postgraduate programmes, where existing literature is scarce. They also offer insight to those about to embark on such programmes of study of what might be expected of them and the potential benefits.

Acknowledgements Grateful thanks to all the participants who gave so willingly of their time and thoughts and Sinead O'Carroll and Katey Warran for help with data collection. Thanks also to Tim Fawns and Derek Jones for their helpful and insightful comments and to Neil Lent for activity theory input.

Open Access This article is licensed under a Creative Commons Attribution 4.0 International License, which permits use, sharing, adaptation, distribution and reproduction in any medium or format, as long as you give appropriate credit to the original author(s) and the source, provide a link to the Creative Commons licence, and indicate if changes were made. The images or other third party material in this article are included in the article's Creative Commons licence, unless indicated otherwise in a credit line to the material. If material is not included in the article's Creative Commons licence and your intended use is not permitted by statutory regulation or exceeds the permitted use, you will need to obtain permission directly from the copyright holder. To view a copy of this licence, visit http://creativecommons.org/licenses/by/4.0/.

\section{References}

Aitken, G., \& O'Carroll, S. (forthcoming 2020). Academic identity and crossing boundaries: The role of the Programme director in postgraduate taught programmes. Higher Education Research and Development.

Aitken, G., Jones, D., Fawns, T., Sutherland, D., \& Henderson, S. (2019). Using Bourdieu to explore graduate attributes in two online Master's programmes. Advances in Health Sciences Education, 24(3), 559-576. https://doi.org/10.1007/s10459-019-09885-6.

Akkerman, S. F. (2011). Learning at boundaries. International Journal of Educational Research, 50(1), 21-25. https://doi.org/10.1016/j.ijer.2011.04.005.

Bayne, S. (2015). What's the matter with 'technology-enhanced learning'? Learning. Media and Technology, 40(1), 5-20. https://doi.org/10.1080/17439884.2014.915851.

Braun, V., \& Clarke, V. (2006). Using thematic analysis in psychology. Qualitative Research in Psychology, 3(2), 77-101. https://doi.org/10.1191/1478088706qp063oa.

Cannon-Bowers, J. A., Salas, E., \& Converse, S. A. (1993). Shared mental models in expert team decisionmaking. In N. J. Castellan Jr. (Ed.), Individual and group decision making (pp. 221-246). Hillsdale: Lawrence Erlbaum.

Collins, H. M. (1990). Artificial experts: Social knowledge and intelligent machines. Cambridge, MA: The MIT Press.

Conole, G., de Laat, M., Dillon, T., \& Darby, J. (2008). Disruptive technologies, pedagogical innovation: what's new? Findings from an in-depth study of students' use and perception of technology. Computers \& Education, 50(2), 511-524. https://doi.org/10.1016/j.compedu.2007.09.009.

Dreyfus, S. E. (2004). The five-stage model of adult skill acquisition. Bulletin of Science, Technology and Society, 24(3), 177-181. https://doi.org/10.1177/0270467604265023. 
Engeström, Y. (1987). Learning by expanding: An activity-theoretical approach to developmental research. Helsinki: Orienta-Konsultit.

Engeström, Y. (2005). Developmental work research: Expanding activity theory in practice. Berlin: Lehmanns Media.

Engeström, Y., \& Miettinen, R. L. (1999). Introduction. In Y. Engeström, R. Miettinen, \& R. L. Punamaki (Eds.), Perspectives on activity theory (pp. 1-16). Cambridge: Cambridge University press. https://doi. org/10.1017/CBO9780511812774.

Engeström, Y., Engeström, R., \& Kärkkäinen, M. (1995). Polycontextuality and boundary crossing in expert cognition: Learning and problem solving in complex work activities. Learning and Instruction, 5(4), 319 336. https://doi.org/10.1016/0959-4752(95)00021-6.

Fawns, T. (2019). Postdigital education in design and practice. Postdigital Science \& Education, 1(1), 132145. https://doi.org/10.1007/s42438-018-0021-8.

Fawns, T., Aitken, G., \& Jones, D. (forthcoming 2020). Ecological teaching evaluation vs. the datafication of quality: Understanding education with, and around, data. Postdigital Science and Education.

Fawns, T., Aitken, G., \& Jones, D. (2019). Online learning as embodied, socially meaningful experience. Postdigital Science and Education, 1(2), 293-297. https://doi.org/10.1007/s42438-019-00048-9 .

Ferreday, D., Hodgson, V., \& Jones, C. (2006). Dialogue, language and identity: Critical issues for networked management learning. Studies in Continuing Education, 28, 223-239. https://doi.org/10.1080 /01580370600947389.

Hager, P., \& Hodkinson, P. (2009). Moving beyond the metaphor of transfer of learning. British Educational Research Journal, 35(4), 619-638. https://doi.org/10.1080/01411920802642371.

Hayes, S. (2018). Invisible labour. Learning and Teaching, 11(1), 19-34. https://doi.org/10.3167 /latiss.2018.110102.

Jamieson, A., Sabates, R., Woodley, A., \& Feinstein, L. (2009). The benefits of higher education study for part-time students. Studies in Higher Education, 34(3), 245-262. https://doi.org/10.1080 /03075070802597010.

Jandrić, P., Knox, J., Besley, T., Ryberg, T., Suoranta, J., \& Hayes, S. (2018). Postdigital science and education. Educational Philosophy and Theory, 50, 893-899. https://doi.org/10.1080 /00131857.2018.1454000.

Jones, C. (2019). Capital, neoliberalism and educational technology. Postdigital Science and Education, 1(2), 288-292. https://doi.org/10.1007/s42438-019-00042-1.

Kember, D., \& Leung, D. (2005). The influence of active learning experiences on the development of graduate capabilities. Studies in Higher Education, 30(2), 155-170. https://doi.org/10.1080/03075070500043127.

Kramsch, C. (1993). Context and culture in language teaching. Oxford: Oxford University Press.

Langemeyer, I., \& Roth, W.-M. (2006). Is cultural-historical activity theory threatened to fall short of its own principles and possibilities as a dialectical social science? Outlines, 2, $20-42$.

Lave, J., \& Wenger, E. (1991). Situated learning: Legitimate peripheral participation. Cambridge: Cambridge University Press. https://doi.org/10.1017/CBO9780511815355.

Miller, G. E. (1990). The assessment of clinical skills/competence/performance. Academic Medicine, 65, S63S67. https://doi.org/10.1097/00001888-199009000-00045.

Su, Y. (2014). Self-directed, genuine graduate attributes: The person-based approach. Higher Education Research \& Development, 33(6), 1208-1220. https://doi.org/10.1080/07294360.2014.911255.

Thorpe, M., \& Edmunds, R. (2011). Practices with technology: Learning at the boundary between study and work. Journal of Computer Assisted Learning, 27(5), 385-398. https://doi.org/10.1111/j.13652729.2010.00405.x.

Tomlinson, M., Enders, J., \& Naidoo, R. (2018). The teaching excellence framework: Symbolic violence and the measured market in higher education. Critical Studies in Education, 00(00), 1-16. https://doi. org/10.1080/17508487.2018.1553793.

Woolgar, S. (Ed.). (2002). Virtual society? Technology, cyberbole, reality. Oxford: Oxford University Press.

Zepke, N. (2014). Student engagement research in higher education: Questioning an academic orthodoxy. Teaching in Higher Education, 19(6), 697-708. https://doi.org/10.1080/13562517.2014.901956. 